\title{
CAPÍTULO 15 \\ A ISENCCÃO DO IMPOSTO PREDIAL E TERRITORIAL URBANO (IPTU) NO MUNICÍPIO DE FLORIANÓPOLIS: FORMA DE VALORIZAÇÃO DO PATRIMÔNIO HISTÓRICO, ARTÍSTICO E CULTURAL
}

\author{
DOI: http://dx.doi.org/10.18616/pgt15
}

Micael Etelvino Fernandes Desengrini

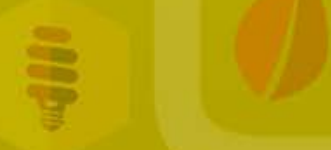

SUMÁRIO 


\section{INTRODUÇÃO}

A tributação dentro da perspectiva municipal é, sem sombra de dúvida, a forma em que o município realiza seu planejamento e desenvolvimento territorial. Dentro desse aspecto, sem a tributação, não há como o município realizar os seus fins sociais, culturais e de desenvolvimento. A principal função do IPTU, que é um imposto real, é traçar uma base sólida para a gestão territorial municipal, dependendo de um cadastro público sólido e de atualização real e constante para o desenvolvimento local.

Portanto, o art. 156, I, da Constituição do Brasil de 1988, bem como outros, atribuíram uma redação dinâmica na gestão territorial, definindo competência aos municípios para instituição do Imposto sobre a Propriedade Predial e Territorial Urbana (IPTU). A sua essência o define como função fiscal, pois, de certa forma, amplia sua função arrecadatória para o desenvolvimento local. Entretanto, há ressalvas.

Sabbag (2016) é enfático ao lecionar que: caberá aos municípios, mediante a edição de lei ordinária municipal, a instituição do IPTU. De acordo com as lições de Mazza (2016), o IPTU é o mais importante exemplo de tributo, lançado de ofício pelo fisco municipal, sendo que a autoridade administrativa competente utiliza as informações cadastrais do contribuinte, sem qualquer participação do devedor, constitui em lançamento e notificação.

Contudo, com o amadurecimento, reflexão e poder de gestão local, os municípios podem utiliza-se dos meios legais de isenção tributária para definir formas de incentivo a sustentabilidade nos ecossistemas urbanos, visando à valorização do patrimônio histórico local.

No caso em tela, em Florianópolis/SC, a Lei Complementar $\mathrm{n}$. 7/1997 (Código Tributário Municipal) define, em seu art. n. 225, VI, a possibilidade de reconhecimento de isenção do imposto, ressalvado o tombamento pelo órgão municipal local, visando à valorização do patrimônio histórico urbano. 


\section{LIÇÕES PRELIMINARES SOBRE OS MUNICÍPIOS}

Primeiramente, antes de adentrar diretamente ao tema de cadastro e IPTU, é fundamental conhecer as lições preliminares e jurídicas que definem os municípios. Logo, sua caracterização e os elementos formadores são de extrema relevância para a pesquisa. No direito brasileiro, estuda-se muito sobre três aspectos distintos: o sociológico, o político e o jurídico.

Ensina Meirelles (2013) a importância de se conhecer o município nas suas funções caracterizantes, pois, de certa maneira, a estruturação local tem finalidade ampla que engloba aspectos essenciais para desenvolvimento com responsabilidade. Dentre esses prismas, destacam-se os seguintes:

[...] Do ponto de vista sociológico, Município brasileiro, como qualquer outro, é o agrupamento de pessoas de um mesmo território, com interesses comuns e afetividades recíprocas, que se reúnem em sociedade para a satisfação de necessidades individuais e desempenho de atribuições coletivas de peculiar interesse local. Sob o aspecto político, o Município brasileiro é entidade estatal de terceiro grau na ordem federativa, com atribuições próprias e governo autônomo, ligado ao estado-membro por laços constitucionais indestrutiveis (CF. arts. 18, 29 e 34, VII, "c"). Na ordem legal, o Município é pessoa jurídica de direito interno (CC, art. 41, III), e, como tal, dotado de capacidade civil plena para exercer direitos e contrair obrigações em seu próprio nome, respondendo por todos os atos de seus agentes (CF, art. 37, § 60) (MEIRELLES. 2013, p. 127-128).

Castro (2016) busca ampliar o conceito de organização do município, buscando balizar o mesmo em seu regramento constitucional. Ele entende que a Constituição Federal de 1988, atual, vigente e posi- 
tivada, conferiu aos municípios o poder de autorregulamentação (art. n . 29 da Constituição Federal de 1988), com regência de iniciativa de Lei Orgânica local, competência do poder legislativo municipal, ou seja, a Câmara de Vereadores, sob o elemento material elencado no (art. n. 31 da Constituição Federal de 1988). Assim, a estruturação elementar foi conferida ao poder local, para a regulação de interesses locais de seu território.

De acordo com Silva (2012), os elementos de autonomia municipal são mais amplos, sendo que ele define como capacidade de gestão dos próprios negócios, isso sendo, de certa forma, respeitado pelo ente que Ihe concede capacidade de gestão. Assim, a Constituição Federal é um elemento que funciona como distribuidor de competências, sendo que, ao rigor da promulgação da Constituição do Brasil, 1988), os municípios incorporaram o poder de auto-organização, governo próprio e competências exclusivas.

O entendimento administrativo ainda deve ser pautado por princípios fundamentais para administração pública, bem como os seus atos. São eles: legalidade, impessoalidade, moralidade, publicidade e eficiência, dentre outros princípios, como o da isonomia (ZANELLA, 2016).

Na visão de Carrazza (2011), importante foi a definição constitucional das receitas municipais, bem como o poder que a Constituição Federal atribuiu aos municípios. Em sua tese ainda, assevera: "Os Municípios têm direito subjetivo à autonomia, e destarte, ao pleno e livre exercício de suas competências tributárias". Ainda, positiva que o ente municipal pode impugnar judicialmente qualquer ato normativo que venha a ferir o seu direito de regulamentar, suas prerrogativas constitucionais na criação do IPTU, ISS, ITBI, bem como os tributos vinculados às taxas e contribuições de melhoria. Destaca, também, a competência para a criação no âmbito municipal do sistema de previdência próprio da municipalidade, sendo que autonomia municipal, de certa forma, beneficia o contribuinte (CARRAZZA, 2011). 


\section{SOBRE FUNÇÃO SOCIAL DA PROPRIEDADE}

A função social da propriedade é um princípio amplo, defendido em vários países do mundo. No Brasil, com relação aos imóveis urbanos, ele está previsto na (Constituição Federal de 1988, art. 182), bem como no Estatuto das Cidades, Lei Federal n. 10.257 do ano de 2001, que regulamentou o dispositivo constitucional. Aduz, ainda, o instituto jurídico do tombamento aos municípios, art. $4, \mathrm{~V}$ letra d, e ainda a diferenciação para imóveis com interesse social em seu art. n. 47, ampliando o enfoque na cidade e sua função social.

Para Sarlet (2005), fazendo jus a efetivação da função social da propriedade. Princípio amplamente debatido na busca de uma construção social plena e justa. Portanto, o que se pretende é demostrar a harmonia do tema proposto com a (Constituição Federal de 1988), ao prever no art. 5o, XXII que "é garantido o direito de propriedade". Indo mais além no inc. XXIII do mesmo artigo, explica que: "a propriedade atenderá a sua função social".

Logo, Alvim e Cambler (2014) destacam que a implementação da função social da propriedade urbana tem como objetivo melhorar, e ainda, em um futuro, eliminar o cinturão da miséria - principalmente no que abrange as grandes cidades, sendo que o país teve uma intensa migração do campo para a cidade, de certo modo, causando desigualdades sociais.

Contudo, a inovação legislativa introduzida na Lei n. 10.257 do ano de 2001, Estatuto das Cidades, faz referência explícita ao poder público, inclusive o municipal, em abordar e implementar elementos de qualidade de vida ao contribuinte e cidadão, elemento debatido no plano diretor municipal.

Assim, define o referido artigo:

Art. 39. A propriedade urbana cumpre sua função social quando atende às exigências fundamentais de ordenação da cidade expressas no plano diretor, assegurando 
o atendimento das necessidades dos cidadãos quanto à qualidade de vida, à justiça social e ao desenvolvimento das atividades econômicas, respeitadas as diretrizes previstas no art. 2ㅇ desta Lei (BRASIL, LEI N. 10.257 DO ANO DE 2001).

A figura do plano diretor é responsável por assegurar a qualidade de vida e a função social da propriedade, elemento fundamental no desenvolvimento municipal, que, de certa maneira, influencia na forma de tributação, bem como nos elementos que integram o cadastro municipal.

Ao promover as políticas de inclusão de qualidade de vida, essas características se refletem no direito tributário e no poder de tributar os contribuintes, na medida em que o fisco Municipal deve adequar-se às características locais e cadastrais do município, dentro da realidade financeira do contribuinte, respeitando princípios constitucionais no ordenamento, tributação e organização municipal.

\section{CONCEITO DE IPTU}

Conforme Pulsen (2016, p. 359), "O IPTU tem como fatos geradores a propriedade, o domínio útil, ou a posse do bem imóvel por natureza ou por acessão física, como definido na Lei Civil, localizado na zona urbana do Município".

Assim sendo, o conceito vai ao encontro do que foi definido junto ao Código Tributário Nacional - Lei n. 5.172, de 25 de outubro de 1966, pois a incidência do IPTU não se limita a imóveis registrados, ou com a devida matrícula no registro de imóveis. Assim, a mera posse do bem já dá ensejo ao direito à cobrança.

Preveem os arts n. 32 e 34 do CTN:

Art. 32. O imposto, de competência dos Municípios, sobre a propriedade predial e territorial urbana tem 
como fato gerador a propriedade, o domínio útil ou a posse de bem imóvel por natureza ou por acessão física, como definido na lei civil, localizado na zona urbana do Município [...].

Art. 34. Contribuinte do imposto é o proprietário do imóvel, o titular do seu domínio útil, ou o seu possuidor a qualquer título (BRASIL, CTN, 1966).

Portanto, para se conhecer sobre a responsabilidade tributária e incidência do tributo, faz-se necessário estudar ou conceituar o Código Civil Brasileiro (Lei n. 10.406, de 10 de janeiro de 2002), no qual se definem as regras de aquisição da propriedade.

O direito de propriedade regula a relação entre as pessoas e a relação dos possuidores com os entes públicos. Paulsen, ainda, é enfático ao afirmar:

A aquisição da propriedade pode decorrer das situações previstas no Código Civil: (i) usucapião (arts. 1.238 a 1.244); (ii) registro de título (arts. 1.245 a 1.247); e (iii) por acessão (arts. 1.248 a 1.259). A "sucessão hereditária" também pode ser considerada como modo de aquisição, pela circunstância de o Código Civil preceituar que "aberta a sucessão, o domínio e a posse da herança transmitem-se desde logo aos herdeiros legítimos e testamentários" (art. 1.784) (2016, p. 360).

Logo, o conceito de propriedade está relacionado aos conceitos citados, e isso gera obrigatoriamente obrigação tributária com relação os bens. Os prédios, terrenos e casas são considerados bens imóveis por natureza. Localizados em área municipal, estão sujeitos à obrigação tributária e incidência de IPTU, ressalvadas as isenções e benefícios fiscais.

Mazza (2015) entende o IPTU como um tributo que somente deve ser cobrado, respeitando a anterioridade anual. Destaca, ainda, o autor sobre o princípio da anterioridade: 
Nesse caso, tais tributos podem ser cobrados sempre em primeiro de janeiro seguinte ao da sua publicação ao ato normativo que os tiver instituído ou majorado, independente do intervalo mínimo de noventa dias, são eles: o imposto de renda, bem como alterações na base de cálculo do IPTU (mudança na planta genérica de valores que implique aumento real no imposto) [...] (MAZZA, 2015, p. 210).

Em Florianópolis, com a possibilidade de instituição de isenção pelo tombamento, o que se busca pelo fisco é incentivar o contribuinte à preservação da história local, sendo o próprio ente municipal o responsável pela fiscalização dos imóveis objetos do benefício fiscal, histórico e cultural.

Segundo Pulsen (2016), o valor venal estabelecido pela prefeitura Municipal, respeitando regras e conceitos da engenharia de avalição, através de normas e métodos específicos, levando em conta toda área urbana, em função dos diversos elementos que integram a composição local, dentre eles: preços correntes de transações e das ofertas a venda no mercado imobiliário, custo de reprodução, características da região onde se situa o imóvel, quadras e quarteirões, polos valorizados e desvalorizadores, idade do imóvel, terrenos encravados, reconstrução, ampliação, dentre outros fatores etc.

O IPTU é um imposto complexo, entretanto a isenção e o tombamento são formas de incentivar o contribuinte na valorização e conexão com os legados históricos do município.

\section{PATRIMÔNIO HISTÓRICO URBANO E PRESERVAÇÃO}

A valorização do patrimônio inclui-se no conceito de meio ambiente cultural, o qual é compreendido pelos bens históricos, artísticos, paisagísticos, ecológicos, científicos e turísticos que servem como referência à cultura estabelecida no local, positivada na Constituição do Brasil de 1988. Conforme seu o art. 216 da Carta Magna: 
Art. 216. Constituem patrimônio cultural brasileiro os bens de natureza material e imaterial, tomados individualmente ou em conjunto, portadores de referência à identidade, à ação, à memória dos diferentes grupos formadores da sociedade brasileira, nos quais se incluem:

I - as formas de expressão; II - os modos de criar, fazer e viver; III - as criações científicas, artísticas e tecnológicas; IV - as obras, objetos, documentos, edificações e demais espaços destinados às manifestações artístico-culturais; $V$ - os conjuntos urbanos e sítios de valor histórico, paisagístico, artístico, arqueológico, paleontológico, ecológico e científico.

§1‥ O Poder Público, com a colaboração da comunidade, promoverá e protegerá o patrimônio cultural brasileiro, por meio de inventários, registros, vigilância, tombamento e desapropriação, e de outras formas de acautelamento e preservação (BRASIL, 1988).

Sobre a temática do sistema de proteção do patrimônio histórico e cultural, Hely Lopes Meirelles ensina:

O conceito de patrimônio histórico e artístico nacional abrange todos os bens, móveis e imóveis, existentes no País, cuja conservação seja de interesse público, por sua vinculação a fatos memoráveis da História pátria, ou por seu excepcional valor artístico, arqueológico, etnográfico, bibliográfico ou ambiental (2011, p. 640).

A norma constitucional busca dar o enfoque de proteção ao patrimônio cultural e reforça os laços de competência concorrente para a fiscalização e proteção com a seguinte redação:

Art. 23, inciso III, "é competência comum da União, dos Estados, do Distrito Federal e dos Municípios, proteger os documentos, as obras e outros bens de valor histórico, artístico e cultural, os monumentos, as paisagens naturais notáveis e os sítios arqueológicos (BRASIL, 1988). 
No caso dos municípios, seguramente compete originar a preservação e incentivo ao patrimônio histórico-cultural local, observada a Constituição do Brasil 1988 em seu art. 30, IX. A política de preservação, tombamento e incentivo à isenção fiscal é uma forma introduzida no município de Florianópolis visando à valorização e ao reconhecimento histórico/cultural.

\section{DA ORGANIZAÇÃO PÚBLICA ADMINISTRATIVA}

Na estrutura municipal, as atribuições sobre o patrimônio cultural estão divididas entre o Instituto de Planejamento Urbano de Florianópolis (IPUF), autarquia municipal, criado em março de 1977, através da Lei n. 1.494, juntamente com o Serviço do Patrimônio Histórico, Artístico e Natural do Município (SEPHAN). Como define o site institucional da Prefeitura Municipal de Florianópolis/SC:

[...] O SEPHAN é responsável por elaborar e executar a política de preservação do patrimônio e cultural de natureza material do município de Florianópolis, visando a manutenção e valorização de sua identidade cultural de natureza material. $O$ acervo cultural - histórico, artístico, arquitetônico e paisagístico é representado pelo casario, espaços, paisagem e geografia, incluindo também malha viária e praças, bens móveis, obras de arte, locais de memória e o acervo arqueológico (pré-histórico, histórico e subaquático).Estas ações contemplam o planejamento, execução, controle, fiscalização e operação vinculadas à preservação do acervo cultural de natureza material, em especial ao planejamento físico, visibilidade e valorização das áreas históricas, monumentos protegidos e suas respectivas áreas de entorno [...] (PREFEITURA FLORIANÓPOLIS/SC, 2017).

Entretanto, a cidade ainda conta com um órgão deliberativo relacionado ao patrimônio cultural. Trata-se do Conselho Municipal de 
Política Cultural (CMPC). É composto por 30 membros, sendo 15 designados pelo Prefeito Municipal e 15 eleitos pela Conferência Municipal de Cultura ou sociedade civil organizada.

Logo, são atribuições do poder público o zelo e toda manutenção e busca pela preservação, tombamento e ações para manter a construção histórica. Entretanto, já foi decidido pelo Tribunal de Justiça do Rio Grande do Sul que os valores históricos preexistem ao tombamento.

CONSTITUCIONAL. ADMINISTRATIVO. IMÓVEL DE VALOR HISTÓRICO. PROTEÇÃO. TOMBAMENTO. DISPENSABILIDADE. REGRAMENTO MUNICIPAL. ARTIGO 30, IX, CF/88. Os valores históricos, artísticos, preexistem ao tombamento e merecem proteção por si mesmos, pelo que representam, independentemente do ato declaratório de tombamento. A não ser assim, a omissão ou, até, a falha do Poder Público, poderia ensejar irreparável perda da memória dos valores em que se estrutura e traduz uma Nação. BEM HISTÓRICO E DEVER DE RESTAURAÇÃO. PROPRIETÁRIO E FALTA DE CAPACIDADE FINANCEIRA. ARTIGO 19, DL N. 25/37. O dever de restauração de bem histórico imputável ao proprietário vai além da mera conservação ordinária do bem, por isso não prescinde da sua capacidade financeira, o que, no caso dos autos, resta indemonstrado. Não bastasse tal, a prova carreada ao feito evidencia a omissão do Poder Público e o agravamento do quadro de degradação do bem, o que, por mais razões, leva a que não se possa imputar ao proprietário, simplistamente, responda, modo objetivo, pelos danos causados pela conduta administrativa ao patrimônio histórico (Apelação Cível N. 70058183799, Vigésima Primeira Câmara Cível, Tribunal de Justiça do RS, Relator: Armínio José Abreu Lima da Rosa, Julgado em 12/03/2014).

Em Florianópolis, a existência de imóveis com valor histórico é notavelmente caracterizada na cidade. Entre os mais diversos tipos e formas de arquitetura e construção. O IPUF buscou organizar de manei- 
ra didática uma cartilha alertando para algumas características sobre a preservação histórica da cidade.

Figura 1 - Preservação do patrimônio histórico - Cartilha IPUF
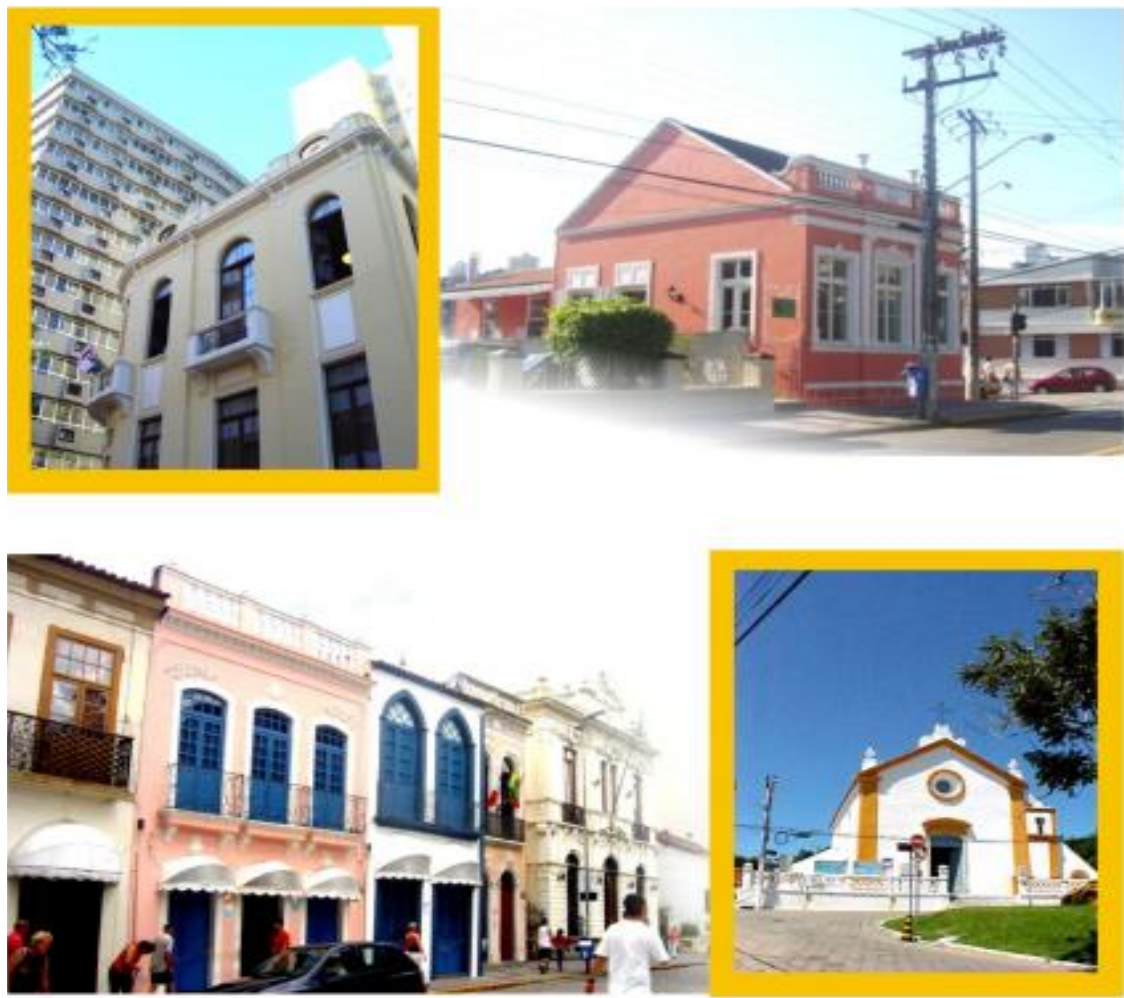

Fonte: PMF/IPUF/SEPHAN. Elaboração: ADAMS, Betina. ALBERS ARAUJO, 2012.

Suzane e NUNES, Maria Anilta. PROJETO RENOVAR: Florianópolis: Política de Preservação do Patrimônio Cultural de natureza material. Florianópolis, agosto/2012. Trazem ao debate sobre a importância da preservação do patrimônio cultural em Florianópolis/SC.

Entretanto, com o auxílio de geotecnologias, atualmente, o município conta com portal de geoprocessamento do plano diretor, permitindo uma visão e classificação dos imóveis localizados em Áreas de 
Preservação Cultural (APC), no qual delimita no mapa sua localização e seus limites geográficos.

Assim, com a inserção dos meios de informação, consegue-se conectar o patrimônio histórico, cultural e artístico a toda coletividade. As informações são públicas, como mandam os princípios da administração. Nas áreas denominadas de preservação cultural, o IPUF e suas ramificações procuram atualizar o cadastro e manter atualizado o sistema de dados, em geoprocessamento corporativo da Prefeitura de Florianópolis/SC.

Figura 2 - Geoprocessamento corporativo, Santo Antônio de Lisboa

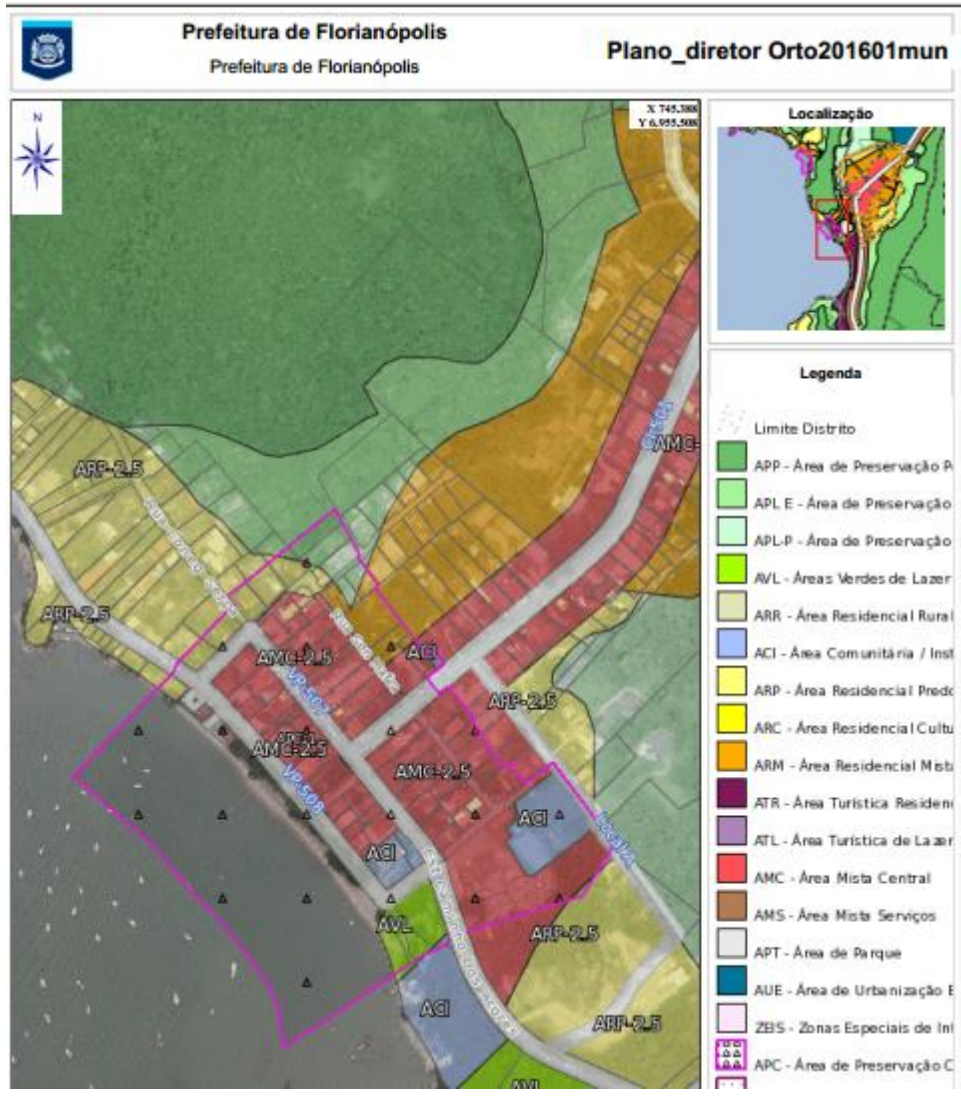

Fonte: PMF - Portal de Geoprocessamento Corporativo 2017. 
Sobre o aperfeiçoamento das ferramentas de Sistema de Informações Geográficas (SIG), entende Farina e Flávia que:

[...] O aperfeiçoamento crescente dos SIG e a automação dos procedimentos administrativos permitem estabelecer o processo de urbanização, com instrumentos cada vez mais sofisticados, que facilitam a tomada de decisões sobre operações urbanísticas com um elevado grau de complexidade. Aliado a esse processo de modernização, é preciso, ainda, transcender o planejamento setorial das cidades, que tem impedido a obtenção de uma visão global de suas problemáticas e a formulação de um modelo integrado para seu desenvolvimento futuro [...] (2006, p.56).

Assim sendo, a cidade de Florianópolis possui a Lei Complementar n. 7/1997. Trata-se do Código Tributário Municipal, o qual define as isenções urbanas de IPTU, dentre elas o tombamento municipal de imóvel com características históricas.

Art. 225 São isentos do Imposto sobre a Propriedade Predial e Territorial Urbana: VI - o imóvel que possua valor histórico, artístico e/ou cultural, tombado por ato da autoridade competente, observado o disposto no $\S 1$ 10 deste artigo (Regulamentado pelo Decreto $n$. 12.608/2014) (Florianópolis. LC n. 7 de 1997).

Carvalho (2017) reconhece que o tombamento é uma forma de intervenção do estado na propriedade, para proteção do ambiente cultural, visando à conservação dos aspectos históricos, artísticos e culturais de um povo. Os bens de interesse local são tombados pelo município, sendo voluntário ou compulsório. Em Florianópolis, o tombamento e a preservação pelo meio jurídico tributário de isenção, previsto na Lei Complementar n. $7 / 1997$, tem se mostrado importante ferramenta como forma de gestão e incentivo à cultura e história municipal. 


\section{CONSIDERAÇÕES FINAIS}

A Constituição do Brasil de 1988, art. 156, I, elenca o IPTU com sendo imposto sobre a Propriedade Predial e Territorial Urbana. A sua essência o define como função fiscal, determinada também pelo Código Tributário Nacional, Lei n. 5.172, de 25 de outubro de 1966, sendo importante para a receita dos municípios.

Entretanto, a proteção e valorização do patrimônio histórico urbano é um dos desafios para a administração pública, tendo em vista a crescente expansão construtiva, incentivada pelo desenvolvimento das cidades e pelo mercado imobiliário.

Porém, os valores históricos e artísticos estão inseridos na cidade e não devem se perder. Portanto, deve a administração pública trabalhar com a cidade histórica e cultural e enfrentar os problemas de crescimento construtivo. Uma forma interessante é a concessão de isenção de IPTU, em determinados imóveis, visando à manutenção e incentivo na preservação arquitetônica, histórica e cultural da cidade.

A Constituição Federal de 1988, em seu art. 216, busca dar enfoque de maneira geral a proteção do patrimônio cultural. Já a legislação do município de Florianópolis, Lei Complementar n. 7/1997 - Código Tributário Municipal, em seu art. 225, amplia o incentivo a preservação do patrimônio histórico e cultural, concedendo isenção do IPTU (Imposto sobre a Propriedade Predial e Territorial Urbana), para imóveis com características históricas e culturais, por meio de ato administrativo de tombamento.

Conclui-se que é função constitucional e local a proteção dos bens imóveis históricos e nota-se claramente na leitura da Constituição Federal de 1988, art. 30, IX, o dever municipal em promover a proteção do patrimônio histórico-cultural local, podendo o administrador público efetivar essa proteção através da isenção de IPTU em imóveis com valor histórico e cultural. 
Em Florianópolis/SC, essa proteção se destaca, inclusive, com a ajuda de ferramentas SIG, no qual são definido como instrumentos de gestão e leitura da cidade que ajudam a compreender os determinados setores e sua classificação no plano diretor, essencial para proteção e a tomada de decisões sobre operações urbanísticas.

Sendo assim, o reconhecimento e incentivo por meio de isenção de IPTU é um desafio para o administrador público, devendo ser prudente para os imóveis com características históricas, indo além da função fiscal tributária e não caracterizando uma renúncia fiscal. Pelo contrário, enquadra-se na busca de preservação das características históricas e culturais definidas pela Constituição Federal de 1988.

\section{REFERÊNCIAS}

ALVIM; CAMBLER, José Manuel de Arruda. Everaldo Augusto. Estatuto da Cidade. Revista dos Tribunais, São Paulo, 2014.

BRASIL. Estatuto da Cidade, Lei Federal n. 10.257 de 10 de julho do ano de 2001: guia para implementação pelos municípios e cidadãos. 2. ed. Brasília: Câmara dos Deputados, Coordenação de Publicações, 2002.

BRASIL. Constituição. Constituição Federal. Brasília, DF: Senado Federal: Centro Gráfico, 1988.

BRASIL. Lei n. 5.172 de 25 de outubro de 1966. Dispõe sobre o Sistema Tributário Nacional e institui normas gerais de direito tributário aplicáveis à União, Estados e Municípios. Disponível em: <http://www.planalto.gov. br/ccivil_03/leis/L5172Compilado.htm>. Acesso em: 14 fev. 2017.

BRASIL. Lei Complementar Municipal. Florianópolis/SC n. 07 de 06 de janeiro do ano de 1997. Código Tributário Municipal da cidade de 
Florianópolis/SC disponível em: https://leismunicipais.com.br/legislacaomunicipal/4571/leis-de-florianopolis. Acesso em: 14 fev. 2017.

CASTRO José Nilo, Direito Municipal Positivo. 6. ed. Belo Horizonte: DelRey, 2006.

CARVALHO. Matheus. Manual de Direito Administrativo. 4. ed., Salvador, Bahia Juspodivm, 2017.

CARRAZZA, Roque Antônio. Curso de Direito Constitucional Tributário. 27. ed. São Paulo: Malheiros, 2011.

FARINA, C. Flávia. Abordagem sobre as técnicas de geoprocessamento aplicadas ao processamento e gestão urbana. FGV. Cadernos do Ebape, v. 4. Disponível em: <www.moodle.ufsc.br>. Acesso em: 12 ago. 2017.

FLORIANÓPOLIS. Prefeitura Municipal. IPUF/SEPHAN. PROJETO RENOVAR: Florianópolis: Política de Preservação do Patrimônio Cultural de natureza material. Florianópolis: IPUF/SEPHAN, 2012.

MAZZA, Alexandre. Manual de Direito Tributário. 2. ed. São Paulo: Saraiva, 2016.

MEIRELLES, Hely Lopes. Direito Municipal Brasileiro. 17. ed. São Paulo: Malheiros, 2013.

PAULSEN, Leandro; MELO, José Eduardo Soares de. IMPOSTOS: Federais, Estaduais e Municipais. 10. ed. Porto Alegre: 2016.

PREFEITURA MUNICIPAL DE FLORIANÓPOLIS/SC. Disponível em: <www. pmf.sc.gov.br>. Acesso em: 20 fev. 2017. 
RIO GRANDE DO SUL. Tribunal de Justiça. Apelação Cível n. 70058183799. Apelante: Ministério Público e município de Rio Grande. Apelado: Miguel Pinto de Oliveira e Solange de Oliveira de Almeida. Relator: Armínio José Abreu Lima da Rosa. Disponível em: <https://tjrs.jusbrasil.com.br/ jurisprudencia/114436607/apelacao-civel-ac-70058183799-rs/inteiroteor-114436610>. Acesso em: 14 ago. 2017.

SABBAG, Eduardo. Manual de direito tributário. 4. ed. São Paulo: Editora Saraiva. 2016.

SARLET, Ingo Wolfgang. A eficácia dos direitos fundamentais. Porto Alegre: Livraria do Advogado, 2005.

SILVA, José Afonso da. Curso de Direito Constitucional Positivo. 35. ed. São Paulo: Malheiros, 2012.

SILVA, José Afonso da. Direito urbanístico brasileiro. 4. ed. São Paulo: Malheiros, 2006.

ZANELLA, Maria Sylvia. Direito administrativo. 29. ed. Rio de Janeiro: Gen. 2016. 